\title{
Relative quantification of human $\beta$-defensins gene expression in pterygium and normal conjunctiva samples
}

\author{
SA'ADATU ALIYU ABUBAKAR $^{1}$, MUHAMMAD MOHD ISA ${ }^{1}$, NAZRI OMAR $^{1}$ and SHEAU WEI TAN $^{2}$ \\ ${ }^{1}$ Ophthalmology Unit, Department of Surgery, Faculty of Medicine and Health Science; \\ ${ }^{2}$ Institute of Bioscience, Universiti Putra Malaysia, Serdang, Selangor 43400, Malaysia
}

Received November 20, 2017; Accepted May 11, 2018

DOI: $10.3892 / \mathrm{mmr} .2020 .11560$

\begin{abstract}
The human ocular surface produces highly conserved cationic peptides. Human $\beta$-defensins (HBDs) serve an important role in innate and adaptive immunity. They are primarily expressed in epithelial cells in response to infection and provide the first line of defence against invading microbes. Defensin $\beta 1$ (DEFB1) is constitutively expressed and regulated by inflammatory mediators including interferon- $\gamma$, lipopolysaccharide and peptidoglycans. DEFB4A is locally induced in response to microbial infection while DEFB109 is induced via Toll-like receptor 2 . The present study examined the expression of the HBD DEFB1, DEFB4A and DEFB109 genes in pterygium. The pterygium tissues and normal conjunctiva samples were obtained from 18 patients undergoing pterygium surgery. The reverse transcription-quantitative polymerase chain reaction method was employed to determine the expression of DEFB1, DEFB4A and DEFB109 genes. The results revealed that the expression of DEFB1 and DEFB4A was significantly higher and upregulated in pterygium samples when compared with normal conjunctiva samples from each patient $(\mathrm{P}<0.05)$, while the expression of DEFB109 was observed to be lower in pterygium samples when compared with normal samples from the same patient. Previous studies have revealed that DEFB1 and DEFB4A genes are present in low concentrations inside the human eye, and they are upregulated during the maturation of keratinocytes, suggesting a possible role in cell differentiation. The DEFB109 gene is present in higher concentrations inside the human eye, though it is newly discovered. It has also been reported that DEFB1 may be involved in carcinogenesis epithelial tumours. Collectively, the current data suggests that HBDs may serve a crucial role in the pathogenesis and
\end{abstract}

Correspondence to: Dr Muhammad Mohd Isa, Ophthalmology Unit, Department of Surgery, Faculty of Medicine and Health Science, Universiti Putra Malaysia, Unit Block B Level 2, Administration Building, Jalan Upm, Serdang, Selangor 43400, Malaysia

E-mail:mmi@upm.edu.my

Key words: human $\beta$ defensin, pterygium, reverse transcription-quantitative polymerase chain reaction development of pterygia, and thus may be considered as novel molecular targets in understanding pterygia development.

\section{Introduction}

Human defensins are widely distributed in epithelial tissues; the defensins family consists of small (2-6 kDa) cationic antimicrobial peptides between 20-50 amino acids with six evolutionary conserved cysteine residues (1). They form disulphide bridges in three pairs, giving rise to three anti-parallel beta sheets structure that assume evolutionary conserved structural fold $(2,3)$. Apart from the six cysteine residues, members of the defensin family have low sequence homology. This observation was believed to result in the difference of characters between all the family members. In humans, $6 \alpha$-defensins and 11 human $\beta$-defensins (HBDs) have been isolated (4). HBDs are produced by epithelial cells lining the body surface and acts as natural antibiotics and immune regulators thus, providing the first line of defence against infection, inflammation and wound healing (4). HBDs have wide-spectrum of antimicrobial and biological activities with little risk of developing resistances. They can also inhibit many steps in viral infection as well as growth of microbes (5). The expression of HBDs is either constitutive or inducible in response to infection or tissue injury $(6,7)$. When induced they normally result in their most effective site-specific response.

HBDs demonstrate proinflammatory activity by binding to certain receptors. For example, HBD2 and HBD1 bind to chemokine receptor 6 (CCR6) leading to increment in chemo-attraction of both CD4+ memory T-helper cells and immature dendritic cells (8). HBDs can also play a role in carcinogenesis of epithelial tumours. Changes in expression of HBDs were observed in epithelial-derived cancers such as prostatic cancer, basal cell carcinoma, oral squamous cell carcinoma (OSCC) and renal cell carcinoma (9). The variation in expression pattern of $\beta$-defensins makes it a suitable tool to investigate its effects in pterygium.

A pterygium is a wedge-shaped fibro-vascular proliferative conjunctival tissue that typically starts on the nasal conjunctiva and extends laterally onto the cornea (10). Typical cases with pterygium are shown in Fig. 1. Pterygium refers to the shape of the tissue, which looks similar to an insect wing.

The prevalence rate of pterygium as reported in different studies varies widely with age, gender and geographical 
location. They are mostly observed in people from tropical climates, but pterygium can be found in over 200 million people worldwide (11). The exact aetiology of pterygium is not fully understood. Previous studies suggested that pterygium was highly associated with ultraviolet radiation (UVR) exposure. Molecular alterations associated with pterygium include loss of heterozygosity $(\mathrm{LOH})$, point mutations of proto-oncogenes (K-ras) and alterations in the expression of tumour suppressor genes (p53 or p63) and nuclear factor (cyclic AMP response element-binding protein CREB) (12). Other findings in pterygium include the frequent detection of HPV DNA, over expression of various ocular surface proteins, including defensins and phospholipases D, as well as the up-regulation of growth factors, such as bFGF or VEGF (13).

Pterygium can cause irregular corneal astigmatism, corneal scarring and restriction of ocular motility. In some severe cases, pterygium may result in visual impairment if it approaches visual axis or chronic ocular surface inflammation $(14,15)$. Pterygium management usually depends on the size and extent of the pterygium. A small pterygium can be treated with mild steroid eye drops (16) while a large size would require surgery (17-19) which is normally enhanced by the use of antimetabolites. Current progress in the biochemical and molecular pathogenesis of pterygium has helped in the use of minimally invasive methods of treatment like minimally invasive pterygium excision MIPE (17). HBDs may influence the pathogenesis of pterygium however; its expression has not been established and has become the focus of this study. In the present study, we examined the expression of the HBD defensin $\beta 1$ (DEFB1), DEFB4A and DEFB109 genes in pterygium and normal conjunctiva epithelial cells to investigate their role in pterygium development.

\section{Materials and methods}

The present study was approved by the Ethics Committee of the Faculty of Medicine and Health Sciences (FMHS), Universiti Putra Malaysia (Serdang, Malaysia). Written informed consent to participate in this study was also obtained from each patient.

The study population consisted of 18 patients all whom underwent pterygium surgery in Hospital Serdang. Based on the inclusion criteria; individuals who had no previous history of pterygium surgery with more than 40 years of age and agreed to participate in the study, were included. Demographic data including, age, gender and the eye affected are shown in Table I. Nine of the patients were male and nine were female. The average mean age of the patients was 57.5 years ranged (40-78 years). Out of 30 patients with pterygium, ten were on the right eye and eight on the left eye.

Collection of samples from patients. Pterygium tissues were obtained from 18 patients undergoing pterygium surgery in Serdang Hospital. The tissues were placed in chilled phosphate-buffered saline (PBS).

Conjunctival impression cytology (CIC) for normal samples (from the same patients) were obtained as described by Tseng's modified method (20,21). Lignocaine hydrochloride $2 \%(w / v)$ (Ain Medicare Sdn Bhd, Kota Bharu, Malaysia) was first injected in the eye, then a D-shaped halve autoclaved cellulosenitrate filter membrane (Sartorius StedimBiotech,
Goettingen, Germany) was placed on the normal conjunctiva for $10 \mathrm{sec}$. The membrane was gently removed and placed into $0.5 \mathrm{ml}$ chilled PBS in $1.5 \mathrm{ml}$ Eppendorf tube. In order to avoid sample contamination, the normal conjunctiva was obtained at the opposite site of the pterygium lesion before excision of the pterygium. Both samples were transported on ice to the laboratory within $3 \mathrm{~h}$ after excision, and then stored at $-80^{\circ} \mathrm{C}$ until used. The tissues were disrupted using syringe and needle then homogenized with QIAshredder (Qiagen, Hilden, Germany).

RNA extraction. The RNA extraction was achieved using RNeasy mini kit (cat. nos. 74104 and 74106) for each sample, according to the manufacturer's manual (Qiagen). The concentration and quality were measured by using Eppendorf Bio spectrometer. A260/A280 was measured for each sample and quality.

cDNA synthesis. The RNA was reverse transcribed into complementary DNA (cDNA) using QuantiTech Rev. Transcription kit (Qiagen) according to the manufacturer's instruction. Briefly, genomic DNA wipe-out buffer was mixed with RNA on ice and incubated at $42^{\circ} \mathrm{C}$ for $2 \mathrm{~min}$, and then placed on ice immediately, Quantscript RT buffer 5X, Quantiscript RT (enzyme) and RT primer mix was also prepared and mixed with the RNA mixture. The final volume of $20 \mu \mathrm{l}$ was incubated at $42^{\circ} \mathrm{C}$ for $20 \mathrm{~min}$, followed by $95^{\circ} \mathrm{C}$ for $3 \mathrm{~min}$ using (Bio-Rad thermal cycler; Bio-Rad Laboratories, Inc., Hercules, CA, USA) and stored at $-20^{\circ} \mathrm{C}$ till used.

Reverse transcription-quantitative polymerase chain reaction (RT-qPCR). The RT-qPCR reaction of DEFB1, DEFB4A and DEFB109 was conducted using SYBR-Green master mix (Qiagen) using C1000 Thermal Cycler and CFX96 real time cycler (Bio-Rad Laboratories, Inc.). The total volume of PCR $(20 \mu \mathrm{l})$ contained $3 \mu \mathrm{l}$ of cDNA, $1 \mu \mathrm{l}$ of $20 \mu \mathrm{M} / \mu \mathrm{l}$ of each primers, $10 \mu \mathrm{l}$ of $2 \mathrm{X}$ SYBR-Green and $5 \mu \mathrm{l}$ of RNase-free water. Negative control (NTC) was also run in each experiment. The list of primers used is shown in Table II. The optimum thermal cycling condition was initially activated at $95^{\circ} \mathrm{C}$ for $3 \mathrm{~min}$, followed by 40 cycles of denaturation at $95^{\circ} \mathrm{C}$ for $20 \mathrm{sec}$, annealing/extension at $60^{\circ} \mathrm{C}$ for $30 \mathrm{sec}$, melting curve analysis at 70 to $90^{\circ} \mathrm{C}$ for $10 \mathrm{~min}$. GAPDH and $\beta$-ACTIN were used as reference genes. The relative quantification of mRNA was done using $2^{-\Delta \Delta \mathrm{Cq}}$ method as described by Livak and Schmittgen (22) using Bio-Rad CFX manager software version 3.1 (Bio-Rad Laboratories, Inc.).

Statistical analysis. Data was expressed as the mean \pm standard error of the mean, and were statistically analysed using SPSS (version 22.0; IBM Corp., Armonk, NY, USA) with significance set at $\mathrm{P}<0.05$ using Student's t-test. Normalised expressions of DEFB1, DEFB4A and DEFB109 in pterygium were compared with normalised expressions of DEFB1, DEFB4A and DEFB109 in normal conjunctiva, respectively.

\section{Results}

Table III summarizes the expression of DEFB1, DEFB4A and DEFB109 results of 18 patients using qPCR. Gene expression analysis was carried out on raw $\mathrm{Cq}$ values using $\Delta \Delta \mathrm{Cq}$ 


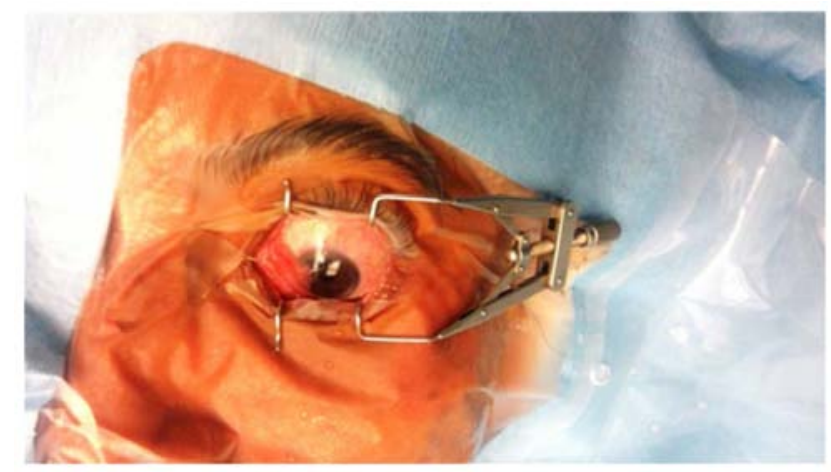

Figure 1. Image of inflammatory nasal pterygium prior to surgery.

method, and the normalization was performed using multiple reference genes, GAPDH and $\beta$-actin. The overall results of mRNA expression of DEFB1, DEFB4A and DEFB109 are shown in Figs. 2-4, respectively. The results are presented as normalized fold changes which were further converted to $\log _{2}$ values to facilitate data presentation.

DEFB1 showed low levels of expression in most normal conjunctiva samples. Its expression was up-regulated in corresponding pterygium samples from the same patient. The expression was significantly increased compared with normal conjunctiva samples $(\mathrm{P}=0.015)$; there was an overall 5 -fold increase in the expression of DEFB1 in pterygium samples compared to normal conjunctiva samples.

DEFB4A showed low level of expression in most normal conjunctiva samples. Its expression was upregulated in corresponding pterygium samples from the same patient. The expression of DEFB4A was elevated in pterygium compared to normal conjunctiva samples, although statistically not significant $(\mathrm{P}=0.064)$, however DEFB4A was not detected in 4 samples of normal conjunctiva within the 40 cycles. There was an approximately 6-fold increase in the expression of DEFB4A in pterygium samples relative to normal conjunctiva samples.

DEFB109 showed high level of expression in most normal conjunctiva samples. Its expression was down regulated in corresponding pterygium samples of the same patient. The expression of DEFB109 was significantly decreased in pterygium compared with normal conjunctiva samples $(\mathrm{P}=0.037)$, There was an overall -1.3 fold change in the DEFB109 expression in pterygium compared to normal conjunctiva samples.

\section{Discussion}

$\beta$-Defensins play important roles in both innate and adaptive immune response (2). $\beta$-defensins are mainly expressed in different types of epithelial cells such as intestinal epithelial, respiratory epithelia, genitourinary tissues, nasolacrimal duct, mammary gland and sometimes in immune cells such as dendritic cells $(2,23-27)$. On the ocular surface, $\beta$-defensins are endogenously produced by epithelial cells. It has been reported that DEFB1, DEFB4A and DEFB109 mRNA expression were detected in scraped corneal epithelial cells and whole conjunctiva tissues $(28,29)$.

Messenger RNA expression of three HBD genes (DEFB1, DEFB4A and DEFB109) in pterygium and normal
Table I. Demographics of the patients.

\begin{tabular}{llcl}
\hline Sample number & Sex & Age (years) & Eye \\
\hline 1 & Female & 68 & $\mathrm{R}$ \\
2 & Male & 68 & $\mathrm{~L}$ \\
3 & Female & 67 & $\mathrm{~L}$ \\
4 & Male & 56 & $\mathrm{R}$ \\
5 & Male & 42 & $\mathrm{R}$ \\
6 & Female & 59 & $\mathrm{R}$ \\
7 & Male & 49 & $\mathrm{R}$ \\
8 & Male & 74 & $\mathrm{R}$ \\
9 & Female & 55 & $\mathrm{~L}$ \\
10 & Male & 53 & $\mathrm{~L}$ \\
11 & Female & 59 & $\mathrm{R}$ \\
12 & Male & 52 & $\mathrm{R}$ \\
13 & Male & 63 & $\mathrm{~L}$ \\
14 & Female & 40 & $\mathrm{R}$ \\
15 & Male & 60 & $\mathrm{R}$ \\
16 & Female & 78 & $\mathrm{R}$ \\
17 & Female & 62 & $\mathrm{R}$ \\
18 & Female & 52 & $\mathrm{~L}$ \\
& & &
\end{tabular}

$\mathrm{R}$, right eye; L, left eye.

conjunctiva of the same patient was investigated using qPCR. Though, the present study is the first to report the effect of these $\beta$-defensins expression in pterygium. The expression of DEFB1 mRNA was detected in all normal conjunctival and pterygium samples in the present study, which was in agreement with previous reports that DEFB1 was constitutively expressed in epithelial cells (24,28,30-32). However, the expression of DEFB4A was positive in 14 normal conjunctiva samples, and positive in all 18 pterygium samples. This finding was in agreement with a number of studies that reported DEFB4A expression by epithelial cells is variable as its expression by normal epithelial occurs only occasionally (inducible) $(33,34)$. DEFB109 was positive in all examined normal conjunctival and pterygium samples (constitutively expressed) which also agrees with previous studies $(29,35)$.

This study also showed that human normal conjunctiva epithelial cells expressed low level of DEFB1 and DEFB4A and high level of DEFB109 mRNA. However, DEFB1 and DEFB4A mRNA expression were up regulated in pterygium while DEFB109 mRNA was down regulated relative to normal conjunctiva samples. Though, the exact mechanisms that regulates the expression of these defensins at the ocular surface are yet to be determined, it has been shown that the expression of $\beta$-defensins on the ocular surface is part of the innate immune response in preventing infection or invasion by microorganism (bacteria, viruses and fungi) $(28,36)$.

DEFB1 and DEFB4A are antimicrobial peptides identified at the ocular surface $(31,37)$, which produces potent antimicrobial effects against common ocular pathogens in vitro. The DEFB1 exists as a single copy gene with several SNPs that have been implicated in the pathogenesis of some chronic inflammatory diseases, including asthma and chronic obstructive 
Table II. List of human $\beta$-defensin primers.

\begin{tabular}{lll}
\hline Primer name & \multicolumn{1}{c}{ Sequence $\left(5^{\prime}-3^{\prime}\right)$} & Product size (bp) \\
\hline $\begin{array}{l}\text { Human } \beta \text {-defensin genes } \\
\text { DEFB1 }\end{array}$ & F: AGCGTCTCCCCAGTTCCTGAAATCCT \\
& R: TCTTCTGGTCACTCCCAGCTCACTTG \\
DEFB4A & F: CATCAGCCATGAGGGTCTTG \\
& R: GGCTTTTTGCAGCATTTTGT \\
FEFB109 & F: TGCAGTAAGAGGTGATTTGG \\
& R: TGACATGATAAGTGGTGTTGG \\
Reference genes & \\
$\beta$-actin & F: CTCCTTAATGTCACGCAGGATTTC \\
& R: GTGGGGCGCCCCAGGCACCA \\
GAPDH & F: CCCATCACCATCTTCCAGAGC \\
& R: CCAGTGAGCTTCCCGTTCAGC \\
\hline
\end{tabular}

DEFB, defensin $\beta ; F$, forward; $R$, reverse.

Table III. DEFB1, DEFB4A and DEFB109 expression in the studied subjects.

\begin{tabular}{|c|c|c|c|}
\hline Patient & Genes & Normal conjunctiva & Pterygium \\
\hline \multirow[t]{3}{*}{$\mathrm{T} 1$} & DEFB1 & Downregulated & Upregulated \\
\hline & DEFB4A & $\mathrm{NE}$ & Downregulated \\
\hline & DEFB109 & Upregulated & Downregulated \\
\hline \multirow[t]{3}{*}{$\mathrm{T} 2$} & DEFB1 & Downregulated & Upregulated \\
\hline & DEFB4A & Downregulated & Upregulated \\
\hline & DEFB109 & Downregulated & Upregulated \\
\hline \multirow[t]{3}{*}{$\mathrm{T} 3$} & DEFB1 & Downregulated & Upregulated \\
\hline & DEFB4A & Downregulated & Upregulated \\
\hline & DEFB109 & Upregulated & Downregulated \\
\hline \multirow[t]{3}{*}{$\mathrm{T} 4$} & DEFB1 & Downregulated & Upregulated \\
\hline & DEFB4A & $\mathrm{NE}$ & Upregulated \\
\hline & DEFB109 & Downregulated & Upregulated \\
\hline \multirow[t]{3}{*}{ T5 } & DEFB1 & Downregulated & Upregulated \\
\hline & DEFB4A & Downregulated & Upregulated \\
\hline & DEFB109 & Upregulated & Downregulated \\
\hline \multirow[t]{3}{*}{ T6 } & DEFB1 & Downregulated & Upregulated \\
\hline & DEFB4A & Downregulated & Upregulated \\
\hline & DEFB109 & Upregulated & Downregulated \\
\hline \multirow[t]{3}{*}{$\mathrm{T} 7$} & DEFB1 & Downregulated & Upregulated \\
\hline & DEFB4A & Downregulated & Upregulated \\
\hline & DEFB109 & Upregulated & Downregulated \\
\hline \multirow[t]{3}{*}{$\mathrm{T} 8$} & DEFB1 & Downregulated & Upregulated \\
\hline & DEFB4A & Downregulated & Upregulated \\
\hline & DEFB109 & Upregulated & Downregulated \\
\hline \multirow[t]{3}{*}{ T9 } & DEFB1 & Downregulated & Upregulated \\
\hline & DEFB4A & Downregulated & Upregulated \\
\hline & DEFB109 & Upregulated & Downregulated \\
\hline \multirow[t]{3}{*}{ T10 } & DEFB1 & Downregulated & Upregulated \\
\hline & DEFB4A & Downregulated & Upregulated \\
\hline & DEFB109 & Upregulated & Downregulated \\
\hline T11 & DEFB1 & Downregulated & Upregulated \\
\hline
\end{tabular}

Table III. Continued.

\begin{tabular}{|c|c|c|c|}
\hline Patient & Genes & Normal conjunctiva & Pterygium \\
\hline & DEFB4A & Downregulated & Upregulated \\
\hline & DEFB 109 & Upregulated & Downregulated \\
\hline \multirow[t]{3}{*}{$\mathrm{T} 12$} & DEFB 1 & Downregulated & Upregulated \\
\hline & DEFB4A & Downregulated & Upregulated \\
\hline & DEFB 109 & Upregulated & Downregulated \\
\hline \multirow[t]{3}{*}{$\mathrm{T} 13$} & DEFB 1 & Downregulated & Upregulated \\
\hline & DEFB4A & Downregulated & Upregulated \\
\hline & DEFB 109 & Downregulated & Upregulated \\
\hline \multirow[t]{3}{*}{$\mathrm{T} 14$} & DEFB 1 & Downregulated & Upregulated \\
\hline & DEFB4A & Downregulated & Upregulated \\
\hline & DEFB 109 & Upregulated & Downregulated \\
\hline \multirow[t]{3}{*}{$\mathrm{T} 15$} & DEFB 1 & Downregulated & Upregulated \\
\hline & DEFB4A & Downregulated & Upregulated \\
\hline & DEFB 109 & Upregulated & Downregulated \\
\hline \multirow[t]{3}{*}{$\mathrm{T} 16$} & DEFB 1 & Downregulated & Upregulated \\
\hline & DEFB4A & Downregulated & Upregulated \\
\hline & DEFB 109 & Upregulated & Downregulated \\
\hline \multirow[t]{3}{*}{$\mathrm{T} 17$} & DEFB 1 & Downregulated & Upregulated \\
\hline & DEFB4A & $\mathrm{NE}$ & Downregulated \\
\hline & DEFB 109 & Upregulated & Downregulated \\
\hline \multirow[t]{3}{*}{ T18 } & DEFB 1 & Downregulated & Upregulated \\
\hline & DEFB4A & $\mathrm{NE}$ & Upregulated \\
\hline & DEFB 109 & Upregulated & Downregulated \\
\hline
\end{tabular}

DEFB, defensin $\beta$; NE, no expression.

pulmonary disease (38-40). Genomic variations in DEFB1 (1) may also contribute to the pathogenesis of pterygium in the presence of specific haplotypes associated with either increased susceptibility to tumors associated inflammation, or protection 


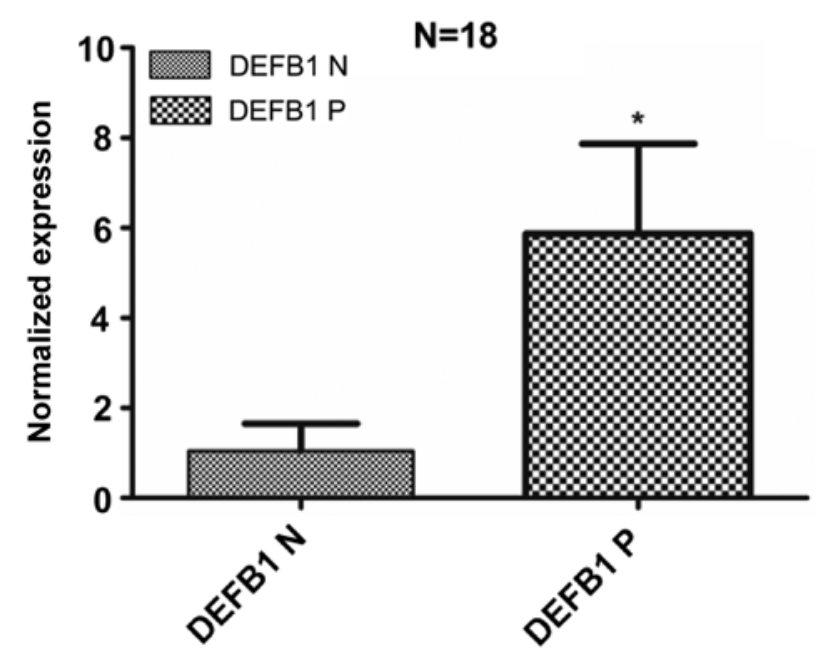

Figure 2. Expression of DEFB1 in normal conjunctiva and pterygium samples. The expression was normalized to GAPDH and $\beta$-actin; where the mean expression is all patients was $n=18$. Data are presented as the mean \pm standard error mean from 30 independent experiments each performed in triplicate. ${ }^{*} \mathrm{P}<0.05$ vs. normal conjunctiva. $\mathrm{N}$, normal conjunctiva samples; $\mathrm{P}$, pterygium samples; DEFB1, defensin $\beta 1$.

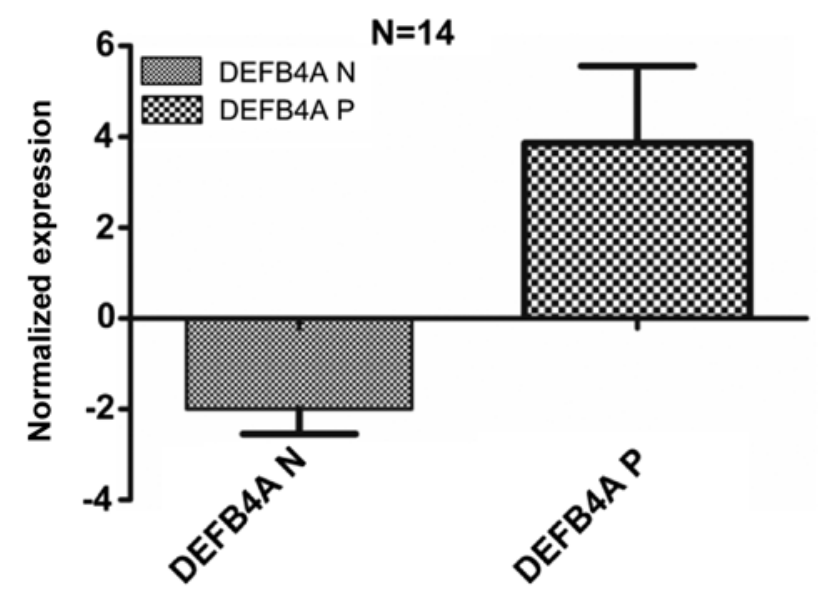

Figure 3. Expression of DEFB4A in normal conjunctiva and pterygium samples. The expression was normalized to GAPDH and $\beta$-actin; where the mean expression is all patients was $n=14$. Data are presented as the mean \pm standard error mean from 14 independent experiments each performed in triplicate. Statistically, no significant difference was observed in DEFB4A mRNA expression between the normal conjunctiva and pterygium. $\mathrm{N}$, normal conjunctiva samples; $\mathrm{P}$, pterygium samples; DEFB4A, defensin $\beta 4 \mathrm{a}$.

from severe infection (viruses). It has been demonstrated that DEFB4A expression is up regulated in response to infection by Gram negative bacteria e.g., $P$. aeruginosa and their products such as lipopolysaccharide, peptidoglycan and lipoproteins, including inflammatory cytokines which consist of IL- $\alpha$ and tumor necrosis factor $(23,34)$. Another study found that human rhinovirus infection induces airway epithelial cell production of DEFB4A both in vitro and in vivo $(23,41)$. The expression of this $\beta$-defensin was also up regulated in the cornea in response to tissue injury and in conjunctiva epithelium of patients with dry eye (42). Moreover, DEFB4A has been found to stimulate human corneal epithelial cell migration and proliferation (36). Also, DEFB4A was recognized as a potential natural antibiotic. The up regulation of DEFB4A in the present study was

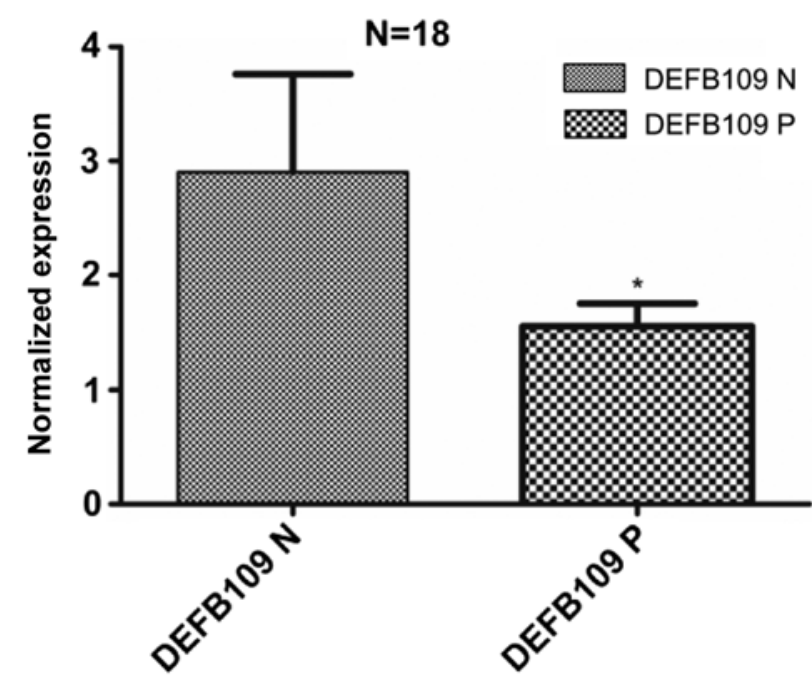

Figure 4. Expression of DEFB109 in normal conjunctiva and pterygium samples. The expression was normalized to GAPDH and $\beta$-actin; where the mean expression is all patients was $n=18$. Data are presented as the mean \pm standard error mean from 18 independent experiments each performed in triplicate. ${ }^{*} \mathrm{P}<0.05$ vs. normal conjunctiva. $\mathrm{N}$, normal conjunctiva samples; P, pterygium samples; DEFB109, defensin $\beta 109$.

considered to indicate an inflammatory response caused by $\mathrm{UV}$ radiation and viral infection in pterygium tissue. Also, absence of detectable DEFB4A in some normal conjunctiva samples (4) indicates that DEFB4A may have a specific influence on innate immune response within the pterygium.

In a recent study by Abedin et al (43), expression of DEFB109, was detected in the ocular surface epithelia, and interestingly its expression was down regulated, thus resulting to decrease in inflammation and infection. Abedin et al (43) demonstrated the down-regulation and constitutive expression of DEFB109, in some of the diseases affecting the ocular surface such as bacterial keratoconjunctivitis, viral keratitis, acanthamoeba keratitis, and dry eye disease. Similarly, the down regulation of DEFB109 was reported after in vitro stimulation of gingival keratinocytes with Candida albicans $(29,44)$. The increase in mRNA expression levels of DEFB1, DEFB4A with decrease in mRNA expression DEFB109 in pterygium epithelial suggests a potential role for the three defensins in the development of the resistant susceptible phenotype. Previous studies reported that $\beta$-defensins provide an initial block to a variety of pathogens on the epithelial surface $(2,45,46)$. It is now well recognized that many antimicrobial peptides possess dual roles as they are capable of killing bacteria or viruses and are able to modulate mammalian cell functions such as migration, proliferation and cytokine production (25). Previous findings indicate that innate and adaptive immune response in the ocular surface is an intricate process likely involving so many processes such as anatomical, biochemical or cellular and humoral factors $(34,47)$.

The underlying cause of increased DEFB1 and DEFB4A expressions, decreased DEFB109 expression in pterygium is not apparent. It is also unclear whether these genes could be functioning as an antimicrobial, pro inflammatory, immune/cellular modulator or both, and whether functionality of these genes affects clinical symptoms of pterygia. Oncogenic viruses, including HPV, CMV, HSV or EBV (48) are being investigated in pterygium but, HPV DNA has been shown to localize quite 
specifically to pterygium in several studies. Taking into account that HPV infection may be associated with pterygium development. A mechanism that might explain the results was proposed based on some recent findings, and the published studies of others. The increase in expressions of DEFB1 and DEFB4A with decrease of DEF109 in pterygium may suggest an immune response to microbial derived stimuli impinging from the systemic explosion of the ocular surface to HPV infection.

Even though, identification of pathogenic determinants in pterygium, including HPV viruses has been an inconsistent finding, and no single pathogenic agent has been categorically identified as sole contributor to pterygium development apart from UV radiation. Nonetheless, the functional role that DEFB1, DEFB4A and DEFB109 play in the development of pterygium could be influenced by viral stimuli within the pterygium.

Finally, qPCR technique provided evidence that both DEFB1 and DEFB4A were constitutively expressed in pterygia and disparately up-regulated, DEFB109 was also constitutively expressed and down regulated in pterygium.

HBDs are involved in various cellular processes. Multitude of functions makes HBDs a promising tool for certain clinical applications. Results, revealed that the expression of HBD1 and HBD2 was significantly higher and up-regulated in some pterygium samples when compared with normal conjunctiva samples from the same patient $(\mathrm{P}<0.05)$ while in HBD9 no significant changed was observed. Thus to our knowledge, this is the first study to determine the expression human $\beta$-defensins in pterygium specifically. HBDs can be a potential target in understanding pterygium development. Furthermore, more research is needed to determine the exact mechanism of defensins in pterygia.

\section{Acknowledgements}

Not applicable.

\section{Funding}

The present study was supported by The Fundamental Research Grant Scheme, Ministry of Education Malaysia (grant no. 5524402).

\section{Availability of data and materials}

The datasets used and/or analyzed during the current study are available from the corresponding author on reasonable request.

\section{Authors' contributions}

MMI, SAA and NO conceived and designed the study. SAA and TSW performed the experiments and collected the data. SAA drafted the manuscript. All authors revised and approved the final version of the manuscript.

\section{Ethics approval and consent to participate}

The present study was approved by the Ethics Committee of the Faculty of Medicine and Health Sciences (FMHS), Universiti Putra Malaysia (Serdang, Malaysia). Written informed consent to participate in the present study was also obtained from each patient.

\section{Patient consent for publication}

Not applicable.

\section{Competing interests}

The authors declare that they have no competing interests.

\section{References}

1. Liu L, Zhao C, Heng HH and Ganz T: The human beta-defensin-1 and alpha-defensins are encoded by adjacent genes: Two peptide families with differing disulfide topology share a common ancestry. Genomics 43: 316-320, 1997.

2. Jia HP, Schutte BC, Schudy A, Linzmeier R, Guthmiller JM, Johnson GK, Tack BF, Mitros JP, Rosenthal A, Ganz T and McCray PB Jr: Discovery of new human beta-defensins using a genomics-based approach. Gene 263: 211-218, 2001.

3. Ganz T: Defensins: Antimicrobial peptides of innate immunity. Nat Rev Immunol 3: 710-720, 2003.

4. Zhou YS, Webb S, Lettice L, Tardif S, Kilanowski F, Tyrrell C, MacPherson H, Semple F, Tennant P, Baker T, et al: Partial deletion of chromosome $8 \beta$-defensin cluster confers sperm dysfunction and infertility in male mice. PLoS Genet 9: e1003826, 2013.

5. Wilson SS, Wiens ME and Smith JG: Antiviral mechanisms of human defensins. J Mol Biol 425: 4965-4980, 2013.

6. Dhople V, Krukemeyer A and Ramamoorthy A: The human beta-defensin-3, an antibacterial peptide with multiple biological functions. Biochim Biophys Acta 1758: 1499-1512, 2006.

7. Wehkamp J, Wang G, Kübler I, Nuding S, Gregorieff A, Schnabel A, Kays RJ, Fellermann K, Burk O, Schwab M, et al: The Paneth cell alpha-defensin deficiency of ileal Crohn's disease is linked to Wnt/Tcf-4. J Immunol 179: 3109-3118, 2007.

8. Yang D, Chertov O, Bykovskaia SN, Chen Q, Buffo MJ, Shogan J, Anderson M, Schröder JM, Wang JM, Howard OM and Oppenheim JJ: Beta-defensins: Linking innate and adaptive immunity through dendritic and T cell CCR6. Science 286: 525-528, 1999.

9. Al-Rayahi IA and Sanyi RH: The overlapping roles of antimicrobial peptides and complement in recruitment and activation of tumor-associated inflammatory cells. Front Immunol 6: 2, 2015.

10. Masters JS and Harris DJ Jr: Low recurrence rate of pterygium after excision with conjunctival limbal Autograft: A retrospective study with long-term follow-up. Cornea 34: 1569-1572, 2015.

11. Lucas RM, McMichael AJ, Armstrong BK and Smith WT: Estimating the global disease burden due to ultraviolet radiation exposure. Int J Epidemiol 37: 654-667, 2008.

12. Nubile $M$, Curcio $C$, Lanzini $M$, Calienno R, Iezzi $M$, Mastropasqua A, Di Nicola M and Mastropasqua L: Expression of CREB in primary pterygium and correlation with cyclin D1, ki-67, MMP7, p53, p63, Survivin and Vimentin. Ophthalmic Res 50: 99-107, 2013.

13. Detorakis ET and Spandidos DA: Pathogenetic mechanisms and treatment options for ophthalmic pterygium: Trends and perspectives (Review). Int J Mol Med 23: 439-447, 2009.

14. Liu L, Wu J, Geng J, Yuan Z and Huang D: Geographical prevalence and risk factors for pterygium: A systematic review and meta-analysis. BMJ Open 3: e003787, 2013.

15. Julio G, Lluch S, Pujol P and Merindano D: Ocular discomfort in pterygium patients. Optom Vis Sci 90: 269-274, 2013.

16. Rachmiel R, Leiba $\mathrm{H}$ and Levartovsky S: Results of treatment with topical mitomycin $\mathrm{C} 0.02 \%$ following excision of primary pterygium. Br J Ophthalmol 79: 233-236, 1995.

17. Bozkir N, Yilmaz S and Maden A: Minimally invasive pterygium surgery: A new approach for prevention of recurrence. Eur J Ophthalmol 18: 27-31, 2008.

18. Ozkurt YB, Kocams O, Comez AT, Uslu B and Dogan OK: Treatment of primary pterygium. Optom Vis Sci 86: 1178-1181, 2009.

19. Varssano D, Shalev H, Lazar M and Fischer N: Pterygium excision with conjunctival autograft: True survival rate statistics. Cornea 32: 1243-1250, 2013.

20. Nelson JD: Impression cytology. Cornea 7: 71-81, 1988. 
21. Singh R, Joseph A, Umapathy T, Tint NL and Dua HS: Impression cytology of the ocular surface. Br J Ophthalmol 89: 1655-1659, 2005.

22. Livak KJ and Schmittgen TD: Analysis of relative gene expression data using real-time quantitative PCR and the 2(-Delta Delta C(T)) method. Methods 25: 402-408, 2001.

23. Vora P, Youdim A, Thomas LS, Fukata M, Tesfay SY, Lukasek K, Michelsen KS, Wada A, Hirayama T, Arditi M and Abreu MT: Beta-defensin-2 expression is regulated by TLR signaling in intestinal epithelial cells. J Immunol 173: 5398-5405, 2004.

24. Alp S, Skrygan M, Schlottmann R, Kreuter A, Otte JM, Schmidt WE, Brockmeyer NH and Bastian A: Expression of beta-defensin 1 and 2 in nasal epithelial cells and alveolar macrophages from HIV-infected patients. Eur J Med Res 10: 1-6, 2005.

25. Musumeci G, Carnazza ML, Leonardi $R$ and Loreto $C$ : Expression of $\beta$-defensin- 4 in 'an in vivo and ex vivo model' of human osteoarthritic knee meniscus. Knee Surg Sports Traumatol Arthrosc 20: 216-222, 2012.

26. Wang XF, Cao RM, Li J, Wu J, Wu SM and Chen TX: Identification of sociodemographic and clinical factors associated with the levels of human $\beta$-defensin-1 and human $\beta$-defensin- 2 in the human milk of Han Chinese. Br J Nutr 111: 867-874, 2014.

27. Suarez-Carmona $M$, Hubert $P$, Delvenne $P$ and Herfs $M$ : Defensins: 'Simple' antimicrobial peptides or broad-spectrum molecules? Cytokine Growth Factor Rev 26: 361-370, 2015

28. Ikeda A, Sakimoto T, Shoji J and Sawa M: Expression of alpha-and beta-defensins in human ocular surface tissue. Jpn J Ophthalmol 49: 73-78, 2005.

29. Otri AM, Mohammed I, Al-Aqaba MA, Fares U, Peng C, Hopkinson A and Dua HS: Variable expression of human Beta defensins 3 and 9 at the human ocular surface in infectious keratitis. Invest Ophthalmol Vis Sci 53: 757-761, 2012.

30. Haynes RJ, McElveen JE, Dua HS, Tighe PJ and Liversidge J: Expression of human beta-defensins in intraocular tissues. Invest Ophthalmol Vis Sci 41: 3026-3031, 2000

31. Huang LC, Jean D, Proske RJ, Reins RY and McDermott AM Ocular surface expression and in vitro activity of antimicrobial peptides. Curr Eye Res 32: 595-609, 2007.

32. Jarczak J, Kościuczuk EM, Lisowski P, Strzałkowska N, Jóźwik A, Horbańczuk J, Krzyżewski J, Zwierzchowski L and Bagnicka E: Defensins: Natural component of human innate immunity. Human Immunol 74: 1069-1079, 2013.

33. McNAMARA NA, Van R, Tuchin OS and Fleiszig SM: Ocular surface epithelia express mRNA for human beta defensin-2. Exp Eye Res 69: 483-490, 1999.

34. McDermott AM: The role of antimicrobial peptides at the ocular surface. Ophthalmic Res 41: 60-75, 2009.

35. Mohammed I, Suleman H, Otri AM, Kulkarni BB, Chen P, Hopkinson A and Dua HS: Localization and gene expression of human beta-defensin 9 at the human ocular surface epithelium. Invest Ophthalmol Vis Sci 51: 4677-4682, 2010.
36. Garreis F, Schlorf T, Worlitzsch D, Steven P, Bräuer L, Jäger K and Paulsen FP: Roles of human beta-defensins in innate immune defense at the ocular surface: Arming and alarming corneal and conjunctival epithelial cells. Histochem Cell Biol 134: 59-73, 2010.

37. Pazgier M, Hoover DM, Yang D, Lu W and Lubkowski J: Human beta-defensins. Cell Mol Life Sci 63: 1294-1313, 2006.

38. Matsushita I, Hasegawa K, Nakata K, Yasuda K, Tokunaga K and Keicho N: Genetic variants of human beta-defensin-1 and chronic obstructive pulmonary disease. Biochem Biophys Res Commun 291: 17-22, 2002.

39. Levy H, Raby BA, Lake S, Tantisira KG, Kwiatkowski D, Lazarus R, Silverman EK, Richter B, Klimecki WT, Vercelli D, et al: Association of defensin beta-1 gene polymorphisms with asthma. J Allergy Clin Immunol 115: 252-258, 2005.

40. Andresen E, Günther G, Bullwinkel J, Lange C and Heine H: Increased expression of beta-defensin 1 (DEFB1) in chronic obstructive pulmonary disease. PLoS One 6: e21898, 2011.

41. Proud D, Sanders SP and Wiehler S: Human rhinovirus infection induces airway epithelial cell production of human beta-defensin 2 both in vitro and in vivo. J Immunol 172: 4637-4645, 2004

42. Meloni M, De Servi B, Marasco D and Del Prete S: Molecular mechanism of ocular surface damage: Application to an in vitro dry eye model on human corneal epithelium. Mol Vis 17: 113-126, 2011.

43. Abedin A, Mohammed I, Hopkinson A and Dua HS: A novel antimicrobial peptide on the ocular surface shows decreased expression in inflammation and infection. Invest Ophthalmol Vis Sci 49: 28-33, 2008.

44. Premratanachai P, Joly S, Johnson GK, McCray PB Jr, Jia HP and Guthmiller JM: Expression and regulation of novel human beta-defensins in gingival keratinocytes. Oral Microbiol Immunol 19: 111-117, 2004

45. McDermott AM: Defensins and other antimicrobial peptides at the ocular surface. Ocul Surf 2: 229-247, 2004.

46. Machado LR and Ottolini B: An evolutionary history of defensins: A role for copy number variation in maximizing host innate and adaptive immune responses. Front Immunol 6: 115, 2015

47. Bolaños-Jiménez R, Navas A, López-Lizárraga EP, de Ribot FM, Peña A, Graue-Hernández EO and Garfias Y: Ocular surface as barrier of innate immunity. Open Ophthalmol J 9: 49-55, 2015.

48. Chalkia AK, Spandidos DA and Detorakis ET: Viral involvement in the pathogenesis and clinical features of ophthalmic pterygium (Review). Int J Mol Med 32: 539-543, 2013. 